\title{
Secondary Palate
}

National Cancer Institute

\section{Source}

National Cancer Institute. Secondary Palate. NCI Thesaurus. Code C34292.

The portion of the embryonic palate that extends from the incisive foramen to the uvula, and is the primordium of the hard and soft divisions of the palate. 